\title{
L-threo- $\mathrm{C}_{6}$-pyridinium-ceramide Bromide, a Novel Cationic Ceramide, Induces NADPH Oxidase Activation, Mitochondrial Dysfunction and Loss in Cell Viability in INS 832/13 $\beta$-cells
}

\author{
Ismail Syed ${ }^{a, c}$ Zdzislaw M. Szulc ${ }^{b} \quad$ Besim Ogretmen ${ }^{b} \quad$ Anjaneyulu Kowluru ${ }^{a}$
}

${ }^{a}$ Beta-Cell Biochemistry Laboratory, John D. Dingell VA Medical Center and Pharmaceutical Sciences, Wayne State University, Detroit, MI; ${ }^{b}$ Departments of Biochemistry and Molecular Biology, Medical University of South Carolina, Charleston, SC 29425; 'Division of Endocrinology, Diabetes and Metabolism, Department of Medicine, Beth Israel Deaconess Medical Center and Harvard Medical School, Boston, MA

\section{Key Words}

Ceramide $\bullet$ Cationic ceramide $\bullet$ NADPH oxidase $\bullet$ Islet beta-cell $\bullet$ Mitochondrial dysfunction

\begin{abstract}
Background: Emerging evidence indicates that exposure of isolated pancreatic $\beta$-cells to elevated glucose [glucotoxicity] or saturated fatty acids such as palmitate [lipotoxicity] or both [glucolipotoxicity] results in excessive intracellular oxidative stress mediated by phagocyte-like NADPH oxidase [Nox2]. Pharmacological evidence also implicates the intracellular generation of ceramide [CER] as one of the mediators of palmitate-induced cytotoxicity of the islet $\beta$ cell. Herein, we investigated the effects of L-threo-C6-pyridinium-ceramide bromide, a novel water soluble cationic ceramide [Ws-CER], on mitochondrial function and cell viability in insulin-secreting INS 832/13 cells. Methods: Ws-CER, was synthesized as we reported earlier. Rac1 activation was quantitated by pull-down assay. Mitochondrial membrane potential was quantitated by JC- 1 staining. Nox 2 subunit expression and caspase- 3 activity were determined by Western blotting. Results: Our findings suggested a marked increase in the Nox2 activation [i.e., ROS generation and subunit expression and activation] in cells exposed to Ws-CER. We also noticed a significant reduction in mitochondrial membrane potential, increased in caspase-3 activity and associated loss in cell viability in Ws-CER-treated cells. Conclusion: Based on these data we conclude that ceramide-induced Nox2-mediated oxidative stress couples mitochondrial dysfunction to loss in cell viability in the pancreatic $\beta$-cell.
\end{abstract}

Copyright (c) 2012 S. Karger AG, Basel 


\section{Introduction}

Recent evidence from multiple laboratories suggests that exposure of pancreatic $\beta$ cells to saturated free fatty acids [e.g., palmitic acid; PA] results in a significant metabolic dysregulation and eventual demise of these cells [1-4]. Multiple mechanisms have been put forth to explain PA-induced metabolic defects; one of these include generation of intracellular oxidative stress [e.g., reactive oxygen species; ROS; 5-10]. One of the potential signaling steps involved in the generation of ROS and intracellular oxidative stress is the activation of the phagocytic NADPH oxidase [Nox2] system, which is a highly regulated membraneassociated protein complex that catalyzes the one electron reduction of oxygen to superoxide anion involving oxidation of cytosolic NADPH $[11,12]$. As we reviewed recently, the Nox2 holoenzyme is comprised of membrane as well as cytosolic components. The membraneassociated catalytic core is a complex consisting of gp91 ${ }^{\text {phox }}, \mathrm{p} 22^{\text {phox }}$ and Rap1. The cytosolic regulatory components include $\mathrm{p} 47^{\mathrm{phox}}, \mathrm{p} 67^{\mathrm{phox}}$ and Rac1. Following stimulation, the cytosolic components of Nox 2 translocate to the membrane for association with the catalytic core for holoenzyme assembly [4].

Several recent studies have demonstrated expression and functional regulation of Nox2 in clonal $\beta$-cells, normal rat islets and human islets by chronic exposure to glucose, PA and proinflammatory cytokines [e.g., IL-1 $\beta$, TNF $\alpha$ and IFN $\gamma$ ]. Moreover, pharmacological inhibition of Nox2 by diphenyleneiodoinium or siRNA-p4 $7^{\text {phox }}$ markedly attenuated glucoseinduced ROS generation and oxidative stress implicating regulatory roles for Nox2 metabolic dysfunction of the $\beta$-cell [13-16]. Along these lines, we have recently demonstrated roles for Nox 2 in the metabolic dysregulation of the islet $\beta$-cell elicited by PA. Using selective inhibitors of de novo biosynthesis of ceramide [CER] from palmitate [e.g., fumonisin B-1], we have suggested roles for intracellularly generated CER in palmitate-induced metabolic dysfunction of the $\beta$-cell [9].

As a logical extension to the above studies, we quantitated, herein, the effects of a novel water soluble cationic ceramide [L-threo-C6-pyridinium-ceramide bromide; Ws-CER; Fig. 1; refs. 17-18] on Nox2 activation, mitochondrial dysfunction, caspase-3 activation and loss of $\beta$-cell metabolic cell viability. This compound has been shown to selectively accumulate in the mitochondrial and nuclear compartments in UM-SCC-22A [human squamous cell carcinoma cells] thereby exerting noxious effects on cell metabolism including inhibition of cell proliferation and induction of apoptosis. To this end we report that Ws-CER induces Nox2 activation, mitochondrial dysfunction, caspase- 3 activation and subsequent loss in $\beta$-cell viability thus validating our hypothesis that CER-mediated effects on $\beta$-cells may in part be due to accelerated Nox2 signaling.

\section{Materials and Methods}

\section{Materials}

L-threo-C6-pyridinium-ceramide bromide [Water Soluble Ceramide; Ws-Cer] was synthesized as we described in [17] . C2-Ceramide was from EMD Millipore [Cat \# 110145]. DCHFDA was from Sigma [Cat \# 35845]. Antiserum directed against p47 phox was from Santa Cruz Biotechnology [Cat\# sc-14015]. Rac1 activation kit was from Cytoskeleton Inc. [Cat \# BK035]. JC-1 assay kit [Cat \# JC100] and Caspasse-3 antibody [Cat \# 9662] were from Cell Technology Inc. MTT assay kit was purchased from Roche [Cat \# 11465007001].

\section{Cell lines and culture conditions}

INS 832/13 cells were cultured in RPMI 1640 medium containing 10\% heat-inactivated fetal bovine serum [FBS] supplemented with $100 \mathrm{IU} / \mathrm{ml}$ penicillin and $100 \mathrm{IU} / \mathrm{ml}$ streptomycin, $1 \mathrm{mM}$ sodium pyruvate, $50 \mu \mathrm{M}$ 2-mercaptoethanol, and $10 \mathrm{mM}$ HEPES (pH 7.4). The cultured cells were subcloned twice weekly following trypsinization and passages 53-59 were used for the study. For Rac1 activation measurements cells were cultured up to $70-80 \%$ confluence in RPMI medium supplemented with $10 \%$ heat-inactivated 


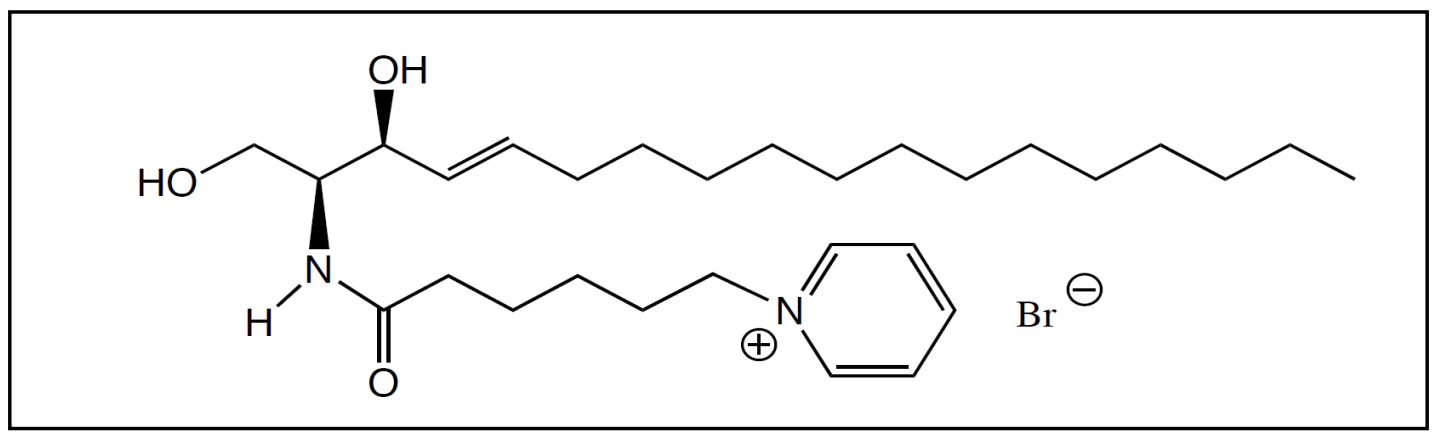

Fig. 1. Structure of L-threo-C6-pyridinium-ceramide bromide (Ws-CER)

FBS prior to inhibitor exposure. Cells were then incubated overnight with low serum-low glucose media followed by incubating in the presence or absence of Ws-CER for different time intervals as indicated in the text.

\section{Quantitation of ROS}

INS 832/13 cells were seeded in a 6-well plate and treated with either diluent or C2-Ceramide or Ws-CER [20 $\mu \mathrm{M}$ ], for $12 \mathrm{hr}$, as indicated in the text. Following to the treatment cells were incubated further in $2^{\prime}, 7^{\prime}$-dichlorofluorescein diacetate (DCHF-DA; $10 \mu \mathrm{M}$ ) at $37^{\circ} \mathrm{C}$ for $30 \mathrm{~min}$. DCHF-DA being a nonpolar compound diffuses rapidly into the cells and hydrolyzes readily by cellular esterases to polar DCFH. In the presence of reactive oxygen species, DCFH is readily oxidized to fluorescent DCF [8-9]. The cells were then washed twice with ice-cold PBS, harvested, sonicated and equal amounts of proteins (50 $\mu \mathrm{g}$ ) were taken to measure fluorescence (Em: $485 \mathrm{~nm}$ and Ex: $535 \mathrm{~nm}$ ) using a luminescence spectrophotometer (Perkin Elmer, Waltham, MA). Protein measurement was carried out by Bradford`s assay.

\section{Rac1 activation assay}

The relative degree of Rac1 activation (GTP-bound form) was determined using Rac1 pull-down assay, as we described in $[9,10]$. In brief, INS 832/13 cells were serum starved overnight and followed by treatments with either diluent or Ws-CER [20 $\mu \mathrm{M}$ ] for $30 \mathrm{~min}$ [INS 832/13 cells] as indicated in the text. Cell lysates $(\sim 250-300 \mu \mathrm{g})$ were clarified by centrifugation. PAK-PBD [p21-activated kinase-p21binding domain] beads $(20 \mu \mathrm{l})$ were added to the supernatant, rotated for $1 \mathrm{~h}$ at $4^{\circ} \mathrm{C}$, and pelleted. The resultant pellet was washed and reconstituted in Laemmli buffer. Proteins were resolved by SDS-PAGE and immunoblotted for determination of GTP-bound Rac1.

\section{Western blot analysis}

Treated INS 832/13 cells were harvested and homogenized in mannitol-protease inhibitor cocktail buffer [250 mM mannitol, $70 \mathrm{mM}$ sucrose, 5 mM HEPES, 1 mM EGTA, 1 mM DTT, and protease inhibitor cocktail]. Protein samples $(\sim 20-30 \mu \mathrm{g})$ were resolved by SDS-PAGE and transferred onto nitrocellulose membrane. The blots, after blocking with 5\% BSA in $20 \mathrm{mM}$ Tris- $\mathrm{HCl}, \mathrm{pH} 7.5,137 \mathrm{mM} \mathrm{NaCl}$, and $0.1 \%$ Tween 20 , were immunoprobed with corresponding primary antibody followed by secondary polyclonal rabbit/ mouse antibody conjugated to horseradish peroxidase $(1: 1,000)$. The protein signal band was detected with enhanced chemiluminescence system (ECL, Amersham Biosciences, Little Chalfont, UK) and developed using Kodak Pro Image $400 \mathrm{R}$ (New Haven, CT). The blots were stripped and reprobed for $\beta$-actin to ensure equal loading and transfer of proteins.

\section{Determination of mitochondrial membrane potential}

INS 832/13 cells were seeded on sterile glass cover slips placed in 6-well plates and grown to confluence and then treated with either diluent or Ws-CER [20 $\mu \mathrm{M}]$ for $12 \mathrm{hr}$. At the end of treatment, cells were incubated with JC-1 (1: 200) dye for $15 \mathrm{~min}$ at $37^{\circ} \mathrm{C}$ in a $5 \% \mathrm{CO}_{2}$ incubator. Cells were then washed thoroughly with assay buffer, mounted onto glass slides, and observed under IX71 inverted fluorescence microscope (X100, Olympus America, Center Valley, Pennsylvania), as described previously (Reference) to estimate the extent of mitochondrial membrane damage. 


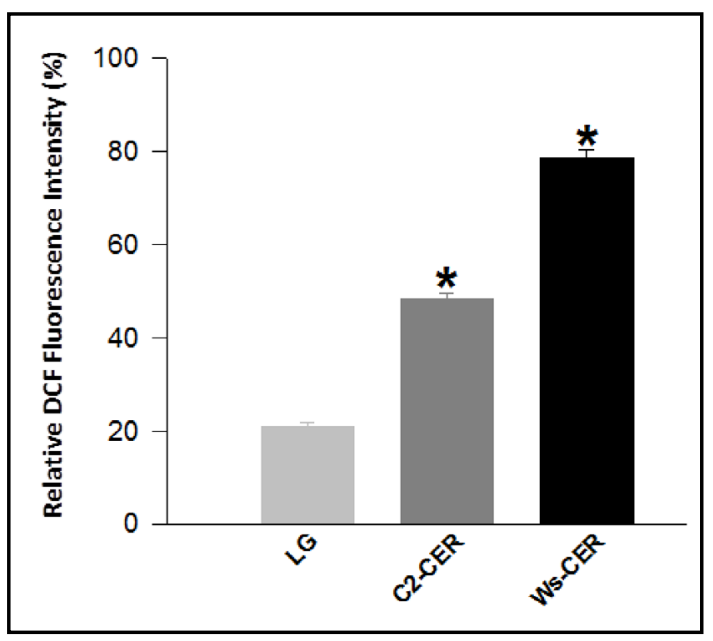

Fig. 2. C2-Ceramide or Ws-CER induces ROS generation in INS 832/13 cells. INS 832/13 cells were treated with either diluent alone or C2Ceramide or Ws-CER [20 $\mu \mathrm{M}$ ], for $12 \mathrm{hr}$. ROS generated via the activation of NADPH oxidase complex was quantitated by DCHFDA assay and is expressed as DCF fluorescence equivalents. Data is mean \pm variance from two independent experiments. ${ }^{*} \mathrm{p}<0.05$ vs. diluent.

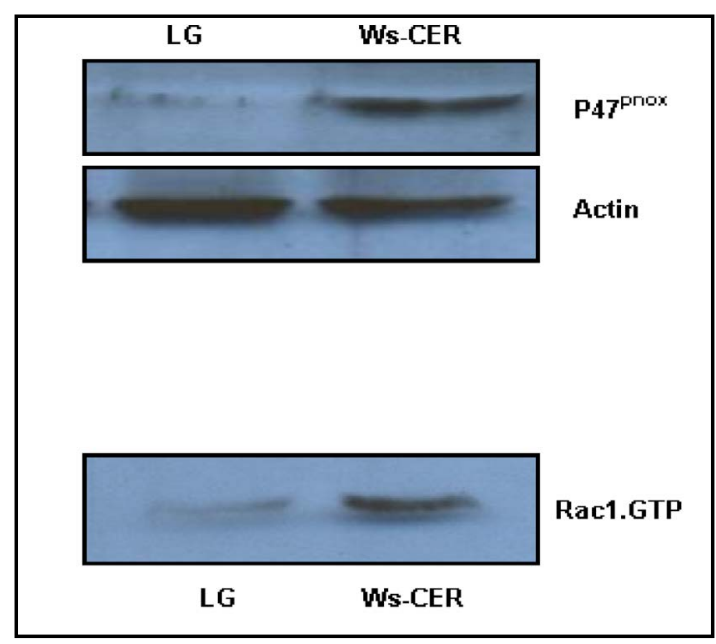

Fig. 3. Ws-CER induces $\mathrm{p} 47^{\text {phox }}$ expression [panel A] and Rac1 activation [panel B] in INS 832/13 cells. Panel A: INS 832/13 cells were treated with either diluent alone or Ws-CER [20 $\mu \mathrm{M}$ ], for $12 \mathrm{hr}$. Lysates collected were separated by SDS-PAGE, transferred onto a nitrocellulose membrane and probed for $\mathrm{p} 47^{\text {phox }}$ or actin and then incubated with the secondary antibody conjugated to HRP for 1 $\mathrm{hr}$ at room temperature. Immune-complexes were detected using ECL kit. A representative blot from two independent experiments is shown here. Panel B: INS 832/13 cells were treated with either diluent alone or Ws-CER [20 $\mu \mathrm{M}$ ] for $30 \mathrm{~min}$ after culturing overnight in low glucose / low serum media. The relative amounts of activated Rac1 [i.e., Rac1-GTP] were determined by PAK-PBD pull down assay. Data are representative of two independent experiments yielding identical results.

\section{Determination of Metabolic Cell Viability}

INS $832 / 13$ cells, seeded at a density of $1 \times 10^{6}$ cells $/ \mathrm{mL}$ in round-bottomed 96 -well plates, were treated with either diluent alone or Ws-CER [0 to $20 \mu \mathrm{M}$ ] as indicated in the text for $12 \mathrm{hr}$. Cell viability was assessed using a colorimetric assay (at 550-690 nm) using 3-[4,5-dimethylthiazolyl-2]-2,5-diphenyltetrazolium bromide (MTT), which measures the reduction of MTT into the blue formazan product by metabolically active cells.

\section{Statistical analysis}

Statistical significance of difference between values were evaluated by Student's t-test or ANOVA where appropriate. $\mathrm{p}<0.05$ was considered to be statistically significant.

\section{Results and Discussion}

At the outset, we assessed the effects of C2-ceramide [C2-CER], a cell permeable analogue of CER, and Ws-CER on ROS generation in INS 832/13 cells. Data in Figure 2 indicate a significant increase [ 2.5-fold] in ROS generation in cells incubated with C2ceramide [ $20 \mu \mathrm{M} ; 12 \mathrm{hr}$; bar 1 vs bar 2]. Importantly, incubation of INS 832/13 cells under similar conditions with Ws-CER resulted in nearly 4-fold increase in ROS generation.

We next examined effects of Ws-CER on the expression of $\mathrm{p} 47^{\text {phox }}$, one of the members of the cytosolic core of Nox2. Data in Figure 3 [Panel A] suggest a marked increase in the 
Syed/Szulc/Ogretmen/Kowluru: Cationic Ceramide Induces Loss in Viability in Islet Betacells

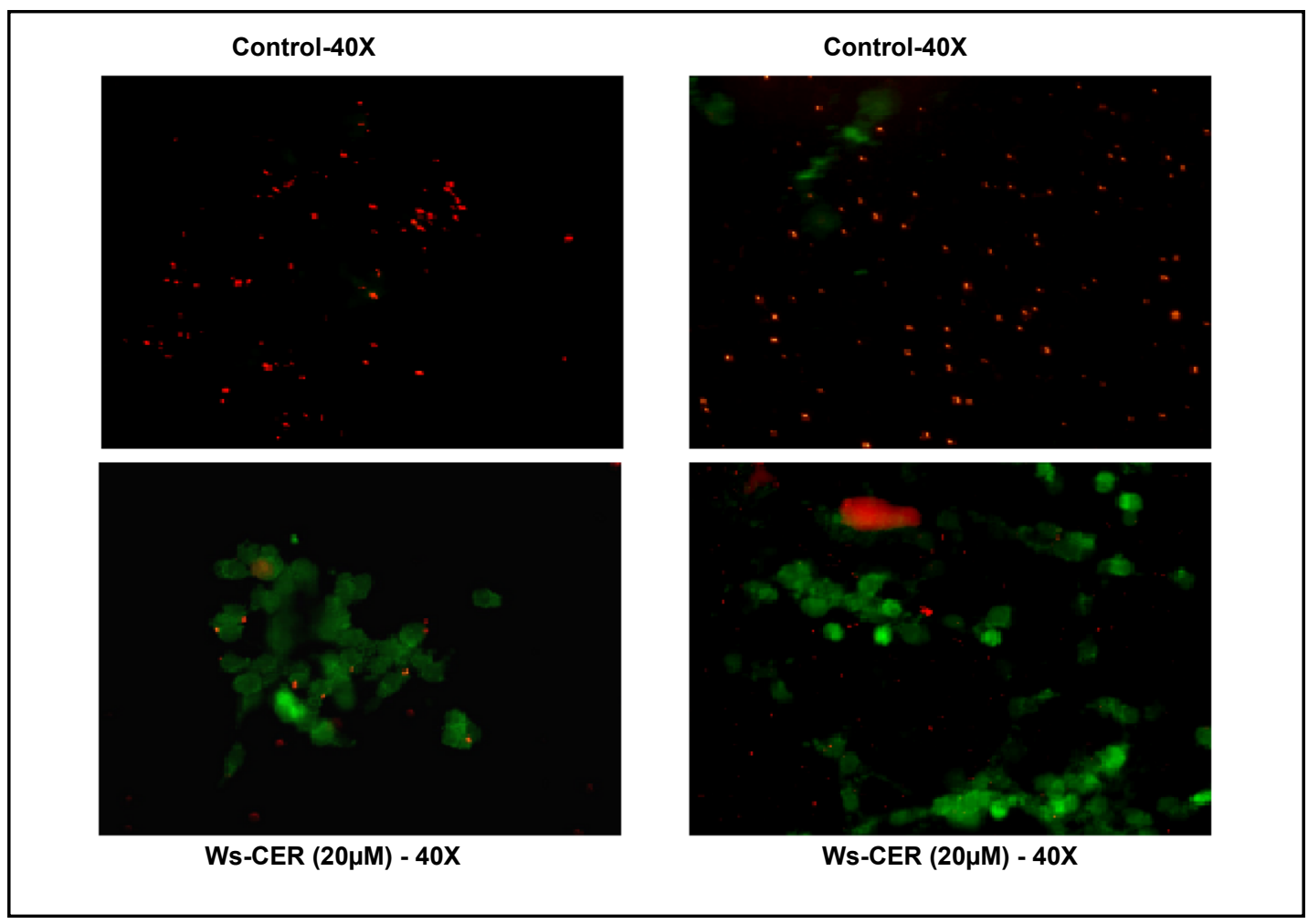

Fig. 4. Ws-CER induces loss in mitochondrial membrane potential in INS 832/13 cells: INS 832/13 cells were treated with either diluent alone or Ws-CER [20 $\mu \mathrm{M}$ ], for $12 \mathrm{hr}$. After treatment cells were incubated with JC-1 stain for $15 \mathrm{~min}$ and observed immediately with a fluorescence microscope for the mitochondrial permeability transition. In live non-apoptotic cells, the mitochondria will appear red following aggregation of the JC-1 reagent. In apoptotic and dead cells the dye will remain in its monomeric form and will appear green with an emission at $530 \mathrm{~nm}$.

expression of p47phox in INS 832/13 cells by Ws-CER under conditions it significantly augmented the ROS generation (as shown in Figure 2). Moreover, we observed a marked increase in the activation of Rac1 [i.e., its GTP-bound confirmation] in INS 832/13 cells following exposure to Ws-CER [Panel B]. Together, data in Figures 2 and 3 suggest that WsCER induces ROS generation in isolated $\beta$-cells, which, may, in part, be due to activation of Nox2 holoenzyme assembly including increased expression of $\mathrm{p} 47^{\text {phox }}$ and activation of Rac1.

In the next series of studies we determined the effects of Ws-CER on mitochondrial membrane potential and caspase- 3 activation in INS 832/13 cells. This was accomplished using the JC-1 staining and immunoblotting methods [see Methods for additional details]. Data in Figure 4 suggest marked reduction in the mitochondrial membrane potential and the associated loss in functional $\beta$-cell mass as evidenced by intense green staining of cells exposed to Ws-CER. Further, loss in mitochondrial membrane potential initiates the caspase cascade and this was evident by increased cleaved caspase-3 in cells treated with Ws-CER (Fig. 5), suggesting the initiation of apoptotic cascade ultimately leading to cell demise.

In the last set of studies, we determined the metabolic cell viability in INS 832/13 cells following exposure to increasing concentrations of Ws-CER. Data depicted in Figure 6 indicate $\sim 75 \%$ loss in cell viability at concentrations $[20 \mu \mathrm{M}]$ of Ws-CER that promoted Nox2 activation, mitochondrial dysfunction and caspase- 3 activation.

One of the main objectives of the current study is to assess the effects of a novel water soluble pyridinium CER on metabolic function of the insulin-secreting INS 832/13 cells. Original studies from Ogretmen's laboratory have synthesized and studied the efficacy of 


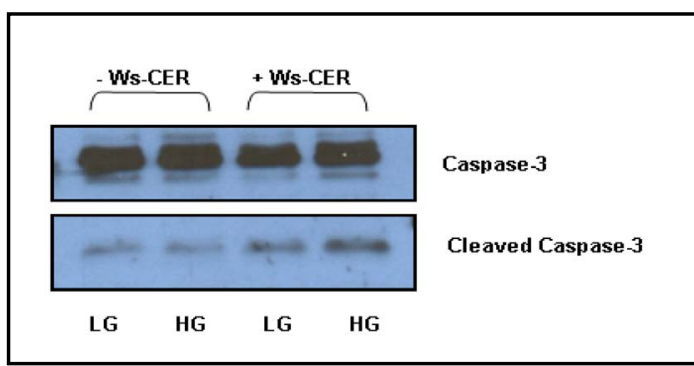

Fig. 5. Ws-CER induces Caspase-3 Activation in clonal pancreatic $\beta$-cells. INS $832 / 13$ cells were treated with either diluent alone or Ws-CER [20 $\mu \mathrm{M}$ ], for 12 hr. Lysates collected were separated by SDS-PAGE, transferred onto a nitrocellulose membrane and probed for anti-caspase-3 overnight and incubated with secondary antibody conjugated to HRP for 1 $\mathrm{hr}$ at room temperature. Immune-complexes were detected using ECL kit. A representative blot from two independent experiments is shown here.

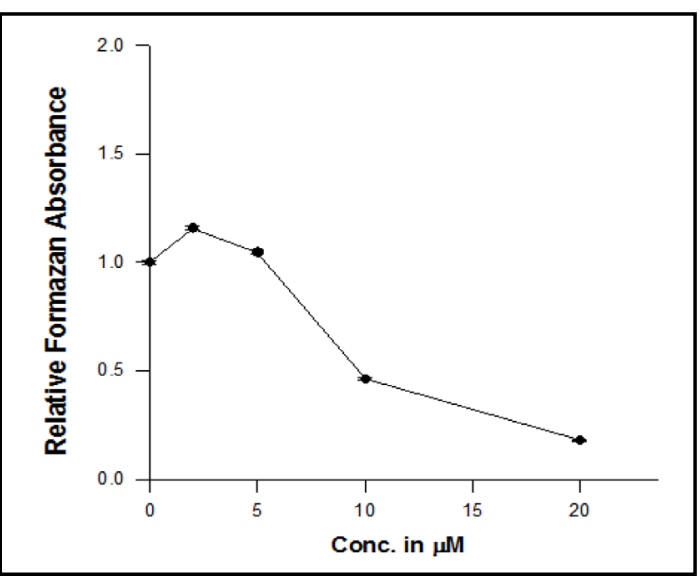

Fig. 6. Ws-CER promotes loss in metabolic cell viability in INS 832/13 cells. INS 832/13 cells were incubated with the different concentrations of WsCER $[0-20 \mu \mathrm{M}]$ as indicated in the figure [see Methods for additional details]. Metabolic cell viability was determined using MTT assay. Data are means \pm variance from two independent experiments.

Ws-CER on human head and neck squamous cell caricinomas in vitro and in vivo. [17]. These investigators observed a significant accumulation of this CER analogue in mitochondrial compartment, and to a lesser extent in the nuclear fraction as early as $1 \mathrm{hr}$. Furthermore, WsCER exerted a significant inhibitory effect on cell growth in these cells [17]. These interesting studies prompted us to investigate potential effects of Ws-CER on $\beta$-cell function, and our results indicate a significant loss in $\beta$-cell survival in INS 832/13 cells following exposure to this CER analogue.

Our current findings are in accord with recent studies from many laboratories including our own suggesting a significant activation of Nox 2 signaling pathway in clonal $\beta$-cells, rodent islets and human islets following exposure to gluco-, lipo-, glucolipotoxic conditions [5-10]. It has also been shown that Rac1 activation step is critical for the assembly and activation of Nox2 holoenzyme. Our current observations further validate that model suggesting that activation of cytosolic components of Nox2 core, including p47 $7^{\text {phox }}$ expression and Rac1 activation initiates the Nox2-mediated generation of ROS intracellularly. Along these lines, published evidence from multiple laboratories suggests that CER-mediated effects are mediated via activation of Rac1. For example, using C2-CER, a permeable analog of CER, Kim and Kim have reported activation of c-fos serum response element via the Rac1 signaling pathway in Rat-2 fibroblasts [19] Using NIH-3T3 cells, Embade et al. have demonstrated novel relationships between FasL generation and CER production in Rac1-induced apoptosis [20]. Lastly, studies by Deshpande and associates have demonstrated the requirement for intracellularly generated CER in Rac-1-induced mitochondrial oxidative stress and premature senescence in human umbilical vein endothelial cells [21]. The above data clearly implicate CER-Rac1 signaling steps in mitochondrial dysfunction, and indeed our current findings further support such a formulation.

In summary, our findings involving the use of a novel pyridinium WS-CER support our original hypothesis that CER-Rac1 signaling axis mediates activation of Nox2 signaling step, which in turn, leads to mitochondrial dysfunction, which is manifested by a measurable decrease in mitochondrial membrane potential and activation of caspase- 3 cascade, leading to loss in metabolic cell viability in insulin-secreting INS 832/13 cells (Fig. 7). Additional studies are needed to assess potential involvement of candidate guanine nucleotide exchange factors for Rac1 [e.g., Tiam1] in the signaling cascade involving Ws-CER-induced loss in viability in these cells. 


\section{Cellular Physiology $\quad$ Cell Physiol Biochem 2012;30:1051-1058 and Biochemistry

Fig. 7. Proposed working model. Based on the data accrued in the current studies and previous studies from our laboratory, we propose that incubation of isolated $\beta$-cells to either C2-CER [Ceramide] or PA [Palmitate] or glucose leads to activation of Rac1 and $\mathrm{p} 47^{\text {phox }}$, which are key members of the Nox2 holoenzyme. These signaling steps promote the assembly and activation of Nox2 culminating in the excessive generation of reactive oxygen species. These, in turn, exert detrimental effects on the mitochondria including reduction in mitochondrial membrane potential leading to the onset of mitochondrial dysfunction and caspase-3 cascade activation, ultimately leading to $\beta$-cell dysfunction and demise.

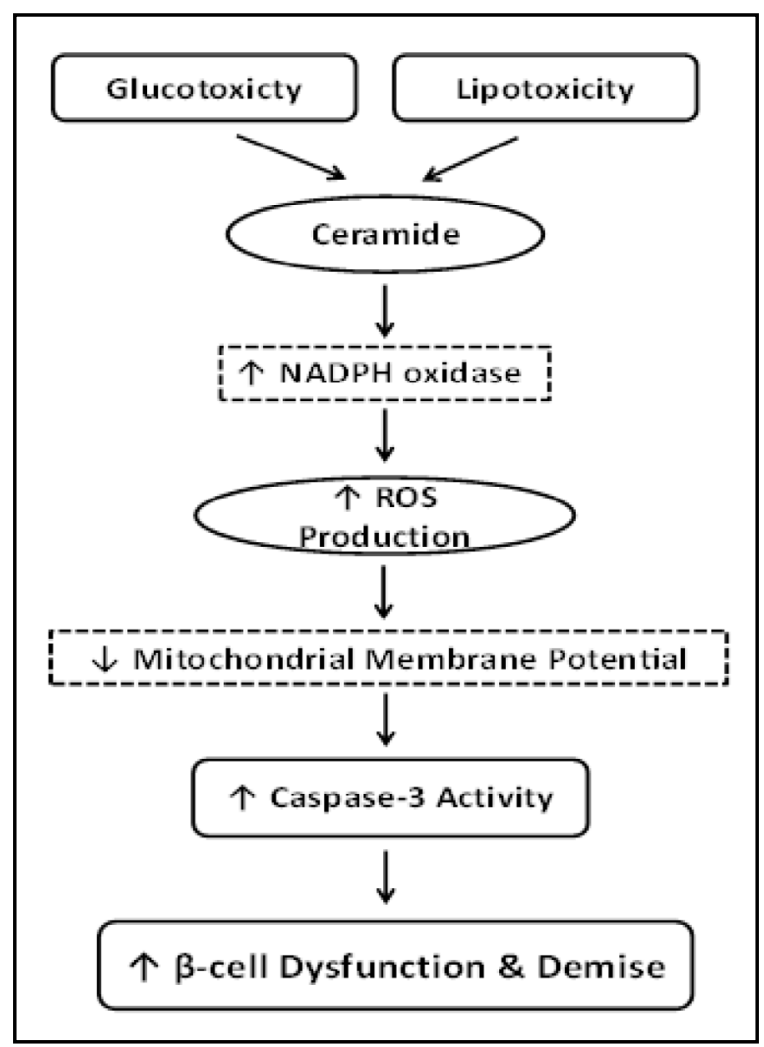

\section{Acknowledgements}

This research was supported in part by a Merit Review award [to AK; 1BX000469] from the Department of Veterans Affairs, Veterans Health Administration, Office of Research and Development [Biomedical Laboratory Research and Development], and by the NIH [DK74921 to AK, and CA97165 to BO]. AK is also the recipient of a Senior Research Career Scientist Award from the Department of VA. The authors would like to thank Prof. Chris Newgard for INS 832/13 cells. The synthesis of Ws-CER was performed by Lipidomics Shared Resource (Medical University of South Carolina), supported by NCI Grants: IP01CA097132 and P30 CA 138313 and NIH/NCRR SC COBRE Grant P20 RR017677. Laboratory space for Lipidomics Shared Resource was supported by the NIH, Grant C06 RR018823 from the Extramural Research Facilities Program of the National Center for Research Resources.

\section{References}

1 Newsholme P, Haber EP, Hirabara SM, Rebelato EL, Procopio J, Morgan D, Oliveira-Emilio HC, Carpinelli AR, Curi R: Diabetes associated cell stress and dysfunction: role of mitochondrial and non-mitochondrial ROS production and activity. J Physiol 2007;583:9-24.

-2 Poitout V, Robertson RP: Glucolipotoxicity: fuel excess and beta-cell dysfunction. Endocr Rev 2008;29:351366.

-3 Evans JL, Goldfine ID, Maddux BA, Grodsky GM: Are oxidative stress-activated signaling pathways mediators of insulin resistance and beta-cell dysfunction? Diabetes 2003;52:1-8.

4 Kowluru A: Friendly, and not so friendly, roles of Rac1 in islet $\beta$-cell function: lessons learnt from pharmacological and molecular biological approaches. Biochem Pharmacol 2011;81:965-975. 

cells

5 Morgan D, Oliveira-Emilio HR, Keane D, Hirata AE, Santos da Rocha M, Bordin S, Curi R, Newsholme P, Carpinelli AR: Glucose, palmitic and pro-inflammatory cytokines modulate production and activity of a phagocyte-like NADPH oxidase in rat pancreatic islets and a clonal cell line. Diabetologia 2007;50:359-369. Inoguchi T, Li P, Umeda F, Yu HY, Kakimoto M, Imamura M, Aoki T, Etoh T, Hashimoto T, Naruse M, Sano H, Utsumi $\mathrm{H}$, Nawata $\mathrm{H}$ : High glucose level and free fatty acid stimulate reactive oxygen species production through protein kinase C-dependent activation of NAD(P)H oxidase in cultured vascular cells. Diabetes 2000;49:1939-1945.

7 Piro S, Anello M, Di Pietro C, Lizzio MN, Patanè G, Rabuazzo AM, Vigneri R, Purrello M, Purrello F: Chronic exposure to free fatty acids or high glucose induces apoptosis in rat pancreatic islets: possible role of oxidative stress. Metabolism 2002;51:1340-1347.

-8 Subasinghe W, Syed I, Kowluru A: Phagocyte-like NADPH oxidase promotes cytokine-induced mitochondrial dysfunction in pancreatic $\beta$-cells: evidence for regulation by Rac1. Am J Physiol Regul Integr Comp Physiol 2011;300:R12-R20.

9 Syed I, Jayaram B, Subasinghe W, Kowluru A: Tiam1/Rac1 signaling pathway mediates palmitate-induced, ceramide-sensitive generation of superoxides and lipid peroxides and the loss of mitochondrial membrane potential in pancreatic beta-cells. Biochem Pharmacol 2010;80:874-883.

10 Syed I, Kyathanahalli CN, Jayaram B, Govind S, Rhodes CJ, Kowluru RA, Kowluru A: Increased PhagocyteLike NADPH Oxidase and ROS Generation in Type 2 Diabetic ZDF Rat and Human Islets Role of Rac1JNK1/2 Signaling Pathway in Mitochondrial Dysregulation in the Diabetic Islet. Diabetes 2011;60:28432852.

11 Babior BM: NADPH oxidase: an update. Blood 1999;93:1464-1476.

12 Geiszt M: NADPH oxidases: new kids on the block. Cardiovasc Res 2006;71:289-299.

$\checkmark 13$ Morgan D, Rebelato E, Abdulkader F, Graciano MF, Oliveira-Emilio HR, Hirata AE, Rocha MS, Bordin S, Curi R, Carpinelli AR: Association of NAD(P)H oxidase with glucose-induced insulin secretion by pancreatic beta-cells. Endocrinology 2009;150:2197-2201.

14 Inoguchi T, Nawata H: NAD(P)H oxidase activation: a potential target mechanism for diabetes vascular complications, progressive beta-cell dysfunction and metabolic syndrome. Cur Drug Targets 2005;6:495501.

15 Sawada F, Inoguchi T, Tsubouchi H, Sasaki S, Fujii M, Maeda Y, Morinaga H, Nomura M, Kobayashi K, Takayanagi R: Differential effect of sulfonylureas on production of reactive oxygen species and apoptosis in cultured pancreatic beta-cell line, MIN6. Metabolism 2008;57:1038-1045.

16 Guichard C, Moreau R, Pessayre D, Epperson TK, Krause KH: NOX family NADPH oxidase in liver and in pancreatic islets: a role in the metabolic syndrome and diabetes? Biochem Soc Trans 2008;36:920-929.

-17 Szulc ZM, Bielawski J, Gracz H, Gustilo M, Mayroo N, Hannun YA, Obeid LM, Bielawska A: Tailoring structure-function and targeting properties of ceramides by site-specific cationization. Bioorg Med Chem 2006;14:7083-7104.

18 Senkal CE, Ponnusamy S, Rossi MJ, Sundararaj K, Szulc Z, Bielawski J, Bielawska A, Meyer M, Cobanoglu B, Koybasi S, Sinha D, Day TA, Obeid LM, Hannun YA, Ogretmen B: Potent antitumor activity of a novel cationic pyridinium-ceramide alone or in combination with gemcitabine against human head and neck squamous cell carcinomas in vitro and in vivo. J Pharmacol Exp Ther 2006;317:1188-1199.

19 Kim BC, Kim JH: Exogenous C2-ceramide activates c-fos serum response element via Rac-dependent signalling pathway. Biochem J 1998;330:1009-1014.

-20 Embade N, Valerón PF, Aznar S, López-Collazo E, Lacal JC: Apoptosis induced by Rac GTPase correlates with induction of FasL and ceramides production. Mol Biol Cell 2000;11:4347-4358.

21 Deshpande SS, Qi B, Park YC, Irani K: Constitutive activation of rac1 results in mitochondrial oxidative stress and induces premature endothelial cell senescence. Arterioscler Thromb Vasc Biol 2003;23:e1-e6. 